\title{
Qualitative Study of EMI Teachers' Required Competencies and Support Needs
}

\section{Sayaka Sugimoto \\ Waseda University}

\section{Reference Data}

Sugimoto, S. (2021). Qualitative study of EMI teachers' required competencies and support needs. In P. Clements, R. Derrah, \& P. Ferguson (Eds.), Communities of teachers \& learners. Tokyo: JALT. https://doi.org/10.37546/JALTPCP2020-09

An increasing number of universities in Japan have been using English as a medium of instruction (EMI) to teach academic subjects. Despite its prevalence, few studies have investigated the competencies required to teach EMI courses. This knowledge gap creates challenges when designing training or support programs for EMI instructors. To contribute to filling this knowledge gap, I conducted semi-structured interviews with instructors of EMI courses at a Japanese university. In these interviews, I explored the difficulties they experienced, competencies they believe EMI instructors should have, and types of support they want to deliver EMI courses effectively. The findings revealed that EMI instructors recognized English competency as a necessary skill but also felt that wider pedagogical and communicative skills are equally important to manage students from diverse linguistic, social, and academic backgrounds. The types of support they wished for were diverse, including multiple human resources and facilities on campus.

日本で益々多くの大学が英語による専門科目の授業 (EMI)を実施している。その普及度にも関わらずEMIを効果的に実施 するのに必要とされる能力についてはあまり調査が行われていない。この知識の差があることでEMl教員を対象とした研修や 支援プログラムの構築が困難になつている。この知識の差を埋めることに貢献するために、本研究ではある日本の大学でEM 授業を実施する教員を対象に半構造化インタビューを行った。インタビューではEMI教員が経験した困難や、EMI教員に必要 だと思われるコンピテンシー、そしてEMIの授業を効果的に行う上で受けたい支援について調查した。結果、EMI教員は英語 力を不可欠なスキルと認識する一方、多様な言語・社会・文化的バリクグラクントを持つ学生に対応するためより広い意味て の教育・コミユニケーション能力も必要と感じていることが分かった。希望する支援は多様でキャンパス内の様々な人的資源 や施設を伴うものであった $\mathrm{n}$ increasing number of universities in Japan have been using English-medium A instruction (EMI) to internationalize their learning environment. EMI refers to "the use of the English language to teach academic subjects (other than English itself) in countries or jurisdictions where the first language of the majority of the population is not English" (Macaro et al., 2018, p.37). Japan's Ministry of Education, Culture, Sports, Science and Technology conducts a bi-annual survey of universities offering courses delivered exclusively in English (excluding those which mainly focus on teaching English language itself). As of 2017 over $40 \%$ (324 out of 777) of the universities in Japan offered EMI courses at the undergraduate level, and 234 offered those courses at the graduate level (Ministry of Education, Culture, Sports, Science and Technology, 2020). University managers have promoted the implementation of EMI courses and programs because it is believed that EMI improves students' English proficiency, attracts international students, and increases institutions' status in the international higher education market (Yonezawa, 2010).

However, in many universities, instructors face multiple challenges when implementing EMI in their classes. Bradford (2016) classified these challenges into four categories: linguistic, cultural, administrative and managerial, and institutional. Among them, the most frequently reported challenges in Japan are linguistic problems, especially those related to student English proficiency. University instructors have expressed concerns over students' English proficiency that is insufficient to learn adequately in the EMI environment (Hanami, 2012; Nakamura, 2003). A few instructors have even argued that EMI can be detrimental for learning the subject covered in the class (Yamamoto, 2011). The problem of linguistic challenges is, in fact, prevalent nationwide. According to a survey of 118 Japanese universities offering undergraduate EMI courses, $51 \%$ of the university representatives considered "insufficient English skills of domestic students" as a major challenge in implementing EMI (Brown, 2017, p. 14).

Another common problem is related to EMI students' diverse backgrounds. According to Brown's survey (2017), the majority of non-degree EMI courses served predominantly 
domestic students, but 18 percent of them were reported to have served either all or predominantly international students, $16 \%$ had a balance of both, and a further $54 \%$ had at least some international students. Students from diverse academic backgrounds tend to have different contextual background knowledge (Tange, 2010) and learning traditions (Eaves, 2009). Combined with the different levels of English proficiency among students, the diversity of students' backgrounds in an EMI classroom makes it difficult for EMI instructors to prepare for and run their EMI courses smoothly (Bradford, 2016).

Moreover, studies have found that EMI instructors experience challenges due to their own limited English proficiency. EMI instructors often consider their own English proficiency level as one of the major barriers to effectively teaching EMI classes (Bradford, 2016; Tange, 2010). EMI instructors in Japan and overseas believe that a "high" level of English proficiency is required to effectively teach an EMI course (Bradford, 2016; Macaro, 2018). However, little is known about the exact level of proficiency required to teach EMI classes. According to a systematic review, there are no empirical studies or institutional requirements that clearly define the English proficiency level needed to teach EMI classes (Macaro et al., 2018). In reality, due to the scarcity of qualified instructors in the majority of non-English-speaking countries (Dearden, 2015), university managers often evaluate instructors' English skills based on subjective observations or the instructors' education in English-speaking countries (Dearden \& Macaro, 2016). There seems to be a gap between managers' and EMI instructors' understanding of the language proficiency level required to teach EMI courses, and instructors often feel that their English skills are inadequate for the task.

While some argue in favor of setting a threshold English proficiency level as a requirement for EMI instructors to teach EMI courses (Kling \& Stæhr, 2012), others argue that the competency required to teach through EMI is not limited to fluency in the language used for the instruction, and thus, defining a language proficiency threshold is insufficient to ensure the effective delivery of EMI classes. Hoare (2003), for example, argued that teaching an academic subject through a second language involves more than just translating the content into the language. He considered "an awareness by teachers of the part language plays in learning within the curriculum" as "a factor in their ability to make content accessible to students" through their second language (p. 3) The implementation of EMI may involve reworking class design, instruction, activities, and materials that instructors use when they teach in their first language. For example, studies have reported that EMI instructors have had to reduce the number of pedagogical tasks (Vinke, 1995) or the content covered in a class (Airey, 2011), or to add additional discussion to ensure student understanding (Bradford, 2016). The literature suggests that teaching through EMI certainly requires English proficiency but other pedagogical competencies may be needed to effectively teach EMI classes.

Several solutions have been proposed to manage the reported problems. A considerable number of researchers have emphasized the need for collaboration between EMI instructors and language experts to manage the linguistic challenges experienced by instructors and students (lyobe \& Li, 2018; Kuwamura, 2019; Lu, 2020; Macaro, 2018). Others have argued that universities should provide training to instructors of EMI courses (Kuwamura, 2018; Yuan, 2019). However, few researchers have directly asked EMI instructors about the skills that are required to teach EMI classes and the types of support they wish to receive to develop these skills. Without this understanding, it remains difficult to design effective training or support programs for EMI instructors.

The purpose of the present study, therefore, is to contribute to filling this knowledge gap by exploring the required competencies and support needs of EMI instructors.

\section{Research Questions}

To achieve the abovementioned research purpose, three research questions were posed:

What types of difficulties do EMI instructors face?

- Which skills/abilities/knowledge do EMI instructors think they need?

- What types of support do EMI instructors want to develop these competencies?

While the second and the third questions are directly related to the research purpose, the first question aims to elicit contextual information from the informants that would help the researcher to better understand their responses to questions 2 and 3 .

\section{Methods}

\section{Data Collection Site}

To explore the three research questions, semi-structured interviews were conducted at a large-scale, top-tier, private university in Tokyo, which both the researcher and participants of the study belong to. This university aggressively promotes the internationalization of educational and research activities on its campus. It received funding from MEXT under the government Global 30 Project (see Ministry of Education, Culture, Sports, Science and Technology, n.d.), and it currently offers more than 50 undergraduate and graduate degree programs entirely in English. 


\section{Semi-Structured Interviews}

Semi-structured interviews were conducted with nine participants from six different departments selected by nonprobability purposive sampling. The selection criteria included full-time status in the university, non-native speaker of English, and experience of teaching at least one EMI course for at least half a semester (6 months). After identifying the eligible participants through social networks and through contact with the department staff, the researcher selected participants so as to maximize the informant diversity in terms of age, faculty status, gender, discipline, course level and content, and the length for which the instructors have taught EMI courses.

The interview questions (Table 1), an information sheet describing the details of the present research, and consent forms were sent to the participants before the interviews. The interviews were conducted between March and September 2020 using Zoom,

Skype, LINE, or land phone, depending on the interviewees' preferences. The interviews typically lasted $60 \mathrm{~min}$. With the participants' permission, the interviews were recorded and transcribed for subsequent analyses.

Table 1

Questions Asked to the Interview Participants

1. $\quad$ Please describe your EMI course(s).

2. Have you experienced any difficulties in preparing for/teaching EMI classes? If yes, please describe your experience. If no, why do you think you did not experience any difficulty?

3. In your opinion, what types of experiences, abilities, and skills are required to teach EMI courses?

4. What types of training and support do you think would be helpful for running EMI courses smoothly?

\section{Data Analysis}

Qualitative content analysis was conducted to analyze the data collected through the interviews. Qualitative content analysis refers to "a research method for the subjective interpretation of the content of text data through the systematic classification process of coding and identifying themes" (Hsieh \& Shannon, 2005, p. 1278). After transcribing the interview audio files, I first identified key concepts as initial coding categories. Second, the categories were sorted and organized by relevance, and finally, a definition was developed for each category.

\section{Ethical Considerations}

This study was conducted with adherence to the guidelines of the institution that the researcher is affiliated to. All the participants received an information sheet that described the purpose and procedure of the study, a set of questions (Table 1), and a consent form written in their preferred language (Japanese or English) before the interview. The form requested permission to record the interview and publish the data in an anonymized format. On the day of the interview, the researcher received oral and written consent from all of the participants.

\section{Results}

The characteristics of the nine informants are summarized in Table 2. All of the participants speak English as a second language. Eight of the nine participants were Japanese nationals. For anonymity, references to the participants' position, gender, department, areas of specialization, and exact course title have been omitted from this paper.

Table 2

Interview Participants

\begin{tabular}{lclcl}
\hline ID & $\begin{array}{c}\text { EMI Experience } \\
\text { (years) }\end{array}$ & \multicolumn{1}{c}{ EMI Subject } & Class size & \multicolumn{1}{c}{ Course Level } \\
\hline 1. & 5 & Law & 20 & Graduate \\
2. & 5 & Cognitive Neuroscience & $5-15$ & Undergrad/Graduate \\
3. & 7 & Chemistry & 10 & Undergrad \\
4. & 3 & Architecture & 70 & Graduate \\
5. & 1 & International Relations & 20 & Graduate \\
6. & 2 & History of Sports & $5-20$ & Undergrad/Graduate \\
7. & 2 & Sociology & 30 & Undergrad \\
8. & 1 & Sports Science & 20 & Undergrad \\
9. & 1.5 & Chemical Engineering & $10-20$ & Graduate \\
\hline
\end{tabular}




\section{Areas of Difficulty}

In line with the findings reported in the literature, the challenges associated with English proficiency were most prominently addressed in the interviews. Nearly all of the informants in this study addressed the limited English proficiency of students and the instructor, as well as the subsequent communication problems, as the major difficulties in administering EMI classes. Four of the informants reported that those problems resulted in increased time, psychological, and physical burdens during the semester. In addition, three of the informants addressed the challenges associated with the lack of a common vocabulary or concepts between two languages. For instance, one interviewee explained that when he teaches in his first language (Japanese), he frequently uses onomatopoeia, such as zarazara and pikapika, to describe the texture of a material. However, there are no such expressions in the English language, so he often struggles to convey the textures of materials to his students. Other linguistic issues addressed by a few of the informants include uncertainty in translating secondary sources written in Japanese into English, lack of textbooks written in English, and emerging needs to implement active learning to ensure students' understanding of lectures but inability to implement it due to a lack of time.

Equally prominent were the challenges associated with the heterogeneity of students' backgrounds. Four of the interviewees emphasized the difficulties associated with preparing for a course without knowing their students' linguistic and academic backgrounds. According to one of the informants, the backgrounds of the students who enroll in his course differ significantly every year. In some years, all of the students are Japanese, and in other years, almost all of them are international students. Due to this unpredictability, this instructor found it challenging to determine something as fundamental as course objectives. According to the interviewees, this problem persisted after the beginning of the class. Five of the participants found it difficult to decide the level of difficulty when delivering each lecture and designing assignments due to various levels of content knowledge, English proficiency, and motivation among students. Additionally, a few of the interviewees mentioned the difficulty associated with managing students who talk too little or too much and handling class discussions with students hailing from different social backgrounds. While Japanese students tend to state their opinion after brainstorming various aspects of an issue, non-Japanese students tend to state their opinions first, followed by the reasons or evidence to support the said opinions. These differences in the ways in which Japanese and non-Japanese students start and end an argument end up becoming a cause of confusion or frustration during class discussions.

\section{Required Competencies}

The competencies that the informants considered important to effectively teach EMI courses included English proficiency, deeper understanding of the specializations/ relevant fields, teaching skills, and communication skills.

The participants addressed the importance of English proficiency together with the importance of domain knowledge. English proficiency was the first competency that came to the minds of six of the informants. However, they consistently emphasized that the instructors' English need not be flawless, and a few even seemed to downplay the importance of having a high level of English proficiency. They described the level of English they needed as "minimum, daily conversation level," "understandable," "doesn't have to be perfect," or "doesn't have to be pronounced beautifully so long as the students can understand." After describing the required English proficiency levels as such, most of the informants emphasized that comprehensive and deep understanding of one's specialization is more important than English. For example, one interviewee explained

What is important is how much knowledge I can translate into English, but it's not just about the English proficiency. It's more about how deeply I actually understand my professional field. It's about whether I can explain the ideas, concepts, and theories from my professional field without taking the easy way of using technical terms in Japanese.

More than half of the informants mentioned the importance of teaching skills, communication skills, or both. The specific examples included abilities to set class goals clearly, use different teaching methods (e.g., active learning) flexibly, and manage student discussions effectively. In terms of communication skills, they further explained it as the ability to communicate with "clarity," "conciseness," "empowering feedback," "encouragement to engage in discussion," and "sense of humor." For instance, a participant noted

EMI has made me realize that I need to make my lecture objectives clearer at the beginning of the class, and what follows should be geared toward that objective. A lecture shouldn't be an on-and-on, endless talk, like I tend to do with my JMI classes. (...) EMI forces me to talk clearly and concisely because I am forced to make real efforts to make my students understand what I really want them to understand.

As the above example demonstrates, teaching skills and clear communication are often described as a combined, inseparable set of skills required in an EMI environment.

Other skills and knowledge that a few of the informants considered important included the ability to search and find adequate amounts of relevant literature in both 
languages quickly, ethical knowledge to integrate secondary sources into class activities while adhering to copyright requirements, ability to understand students, and work experience in English-speaking environments.

\section{Support Needs}

All of the participants expressed their desire to receive additional support through faculty development (FD) programs. The focus of the FD programs they desired varied significantly from those covering basic instruction for EMI implementation to more advanced programs involving knowledge sharing and collaborations with professionals within/across disciplines. For example, a few of the informants sought a one-time lecture to introduce frequently used English phrases in an EMI class or a series of workshops teaching how to design an EMI class, how to write a course syllabus, how to implement active learning, and how to utilize information and communication technologies in an EMI environment. Others wanted opportunities for knowledge-sharing with faculty members and professionals from other disciplines. For instance, one informant summarized the importance of creating a space through FD where EMI teachers can learn collaboratively and efficiently:

No one really seems to know (how to run EMI effectively), so it's probably good to have a platform to share the problems experienced by instructors. Currently, each instructor makes independent efforts for EMI through repeated trial and error endeavors. We rarely have the opportunity to talk about it in my department.

In addition to knowledge sharing, some of the informants expressed interest in undertaking collaborative efforts to improve the quality of their classes, such as sharing of lecture recordings that demonstrate the best EMI practices, inviting professional observers to their lectures to receive feedback, and having opportunities to teach or attend EMI classes in overseas universities.

Although it was not as prominent as the informants' interest in FD programs, about half of the respondents expressed the desire to receive support that helps them to manage the linguistic problems of their students and those of their own. Four of the participants highlighted the importance of students seeking additional English support outside their class (i.e., writing center) to manage assignments and class discussions. Based on these experiences, one informant wished to convey to students that English is "an easy, relaxed language for communication" and "do not to be afraid to speak up." If students can develop confidence and comfort in expressing themselves in English, he believed that his class would proceed smoothly. In addition, four of the informants expressed their wish for support from teaching assistants (TAs) who speak English as a second language, for instance, in terms of proofreading course materials, such as lecture slides and course syllabus, stimulating class discussions, or managing students' questions on a one-to-one basis. In terms of receiving support from language experts (i.e., faculty members who specialize in ESL), half of the informants said they had no such personnel in their department, and the rest declined the idea stating that their involvement would cause conflicts of interest when determining the learning objectives and designing courses.

About half of the respondents expressed interest in receiving support from academic staff members, such as librarians and administrators. After explaining how time consuming it was to prepare course materials, four of the informants wished for librarians to help them check the availability of specific books, journals, and other materials or to improve online databases to ensure the accessibility of items relevant to their EMI courses for their students. Three of the informants emphasized the importance of administrative support to identify registered students' academic backgrounds or completion levels within the curriculum before the start of the semester and to set rules regarding assignments to maintain consistent standards across EMI courses within a curriculum.

\section{Discussion}

In terms of difficulties, the findings largely concur with those reported in literature. Challenges pertaining to students' limited English proficiency (Hanami, 2012; Nakamura, 2003), instructors' limited English proficiency (Bradford, 2016; Tange, 2010), and instructors' increased workload (Tsuneyoshi, 2005) were addressed during the interviews. Similarly, the challenges arising from diverse student backgrounds were consistent with those reported in the literature. Consistent with Brown's nationwide survey (2017), all of the informants in this study had both domestic and international students of differing content knowledge levels (Tange, 2010) and English proficiency levels (Bradford, 2016) in their classes. The present study supplemented these findings by adding that EMI students had differing levels of motivation to learn and different ways of engaging in discussion depending on their sociocultural backgrounds. Furthermore, the results emphasized the changeability and unpredictability of student enrollment every year. With such unpredictability, even those informants with relatively longer EMI teaching experience barely seemed to have benefitted from the accumulation of experience.

Considering the wide range of challenges faced by EMI instructors, it is unsurprising that the study participants believed that English proficiency is not the only skill required 
to teach EMI classes. To manage the difficulties emerging from EMI implementations, EMI instructors need not only English skills but also deeper understanding of their own professional field, as well as superior teaching and communication skills, to deliver the contents through English to diverse student bodies. In this light, the seeming inconsistency of the informants' perceptions with regards to the English level required to teach via EMI was interesting. Although the participants hailed from different disciplines, the challenges associated with English proficiency appeared to be common among them, affecting all stages of EMI implementation from class design to assignment provision. However, when asked about the required competencies, the participants tended to downplay the importance of having high levels of English proficiency. In several studies (Dearden \& Macaro, 2016; Tan \& Lan, 2011), a few science and math instructors at the university level exhibited a similar tendency to downplay the need for high levels of English proficiency to conduct EMI classes because of their belief that teaching those subjects involve using more of numbers and signs than sentences. While the respondents of those studies belonged to specific academic fields, the respondents of the present study hail from diverse fields. Future research should examine the extent to which the attitude identified among the informants of this study is prevalent and investigate the underlying reasons.

Equally interesting was the distinct lack of interest among the participants in receiving support from language experts despite the clear presence of linguistic challenges that all of the informants were aware of. The informants clearly expressed interest in receiving English-language support, such as introduction of English expressions used frequently in EMI classes and proofreading of course materials. However, they wanted to receive such support through faculty programs and TAs, not from linguistic experts. By contrast, the existing literature emphasizes the importance of collaboration between content and language specialists (lyobe \& Li, 2018; Kuwamura, 2019; Lu, 2020; Macaro, 2018). As addressed above, EMI researchers define EMI as the teaching of specialized subjects and not the English language itself. EMI instructors often consider themselves not responsible for their students' English problems (Yip et al., 2007). However, this definition is not necessarily agreed upon universally among professors from different fields (Macaro et al., 2018) or among students (Sugimoto, 2020). Considering these factors, EMI instructors may express concern about any possible conflicts of interest when collaborating with language experts, or they may simply wish to avoid the additional time burden that collaboration could entail. Moreover, they possibly do not know how such a collaboration could work and the benefits it could generate. Future studies should examine whether EMI instructors' attitudes are derived from actual collaborative experience, or a lack of knowledge/resources.

\section{Limitations of the Study}

This was an exploratory study that examined the EMI experiences of nine participants belonging to the same university in Japan. Since it was a small-scale study in a specific university context, the findings cannot be generalized to other university contexts. The informants in this study belonged to six departments, and no informants from the other departments participated in the study. Additionally, the social desirability effect may have influenced the informants' responses to the interviewer's questions. Considering that informants and the researcher belonged to the same institution, the informants might have responded to the questions in a way that seemed more acceptable. Despite these limitations, the results identified recurring themes that have been addressed in previous studies and presented new insights related to EMI instructors' support needs, which have not been sufficiently addressed in EMI research.

\section{Conclusion}

This study explored the competencies required to teach EMI courses and the types of support that EMI instructors wish to receive to administer their classes effectively. To the best of the researcher's knowledge, this is the first study that examined those themes in the Japanese university context, and it yielded several contributions to EMI research and practice. First, it suggests that EMI is not a simple translation of course content into English but it involves multiple changes in class instructions and interactions; and thus, the required competencies are not limited to English proficiency but pertain to wider pedagogical and communicative skills. Second, the findings of this study indicated that there are many ways in which various academic staff, including university administrators, librarians, and TAs, could contribute to managing the challenges that instructors face when implementing EMI.

\section{Bio Data}

Sayaka Sugimoto is an Assistant Professor in the Faculty of Human Sciences at Waseda University. Her research focuses on EMI in higher education. She is currently involved in research identifying the support needs of EMI students and instructors and in projects to utilize Information Communication Technologies for effective EMI implementation. <sayakasugimoto@gmail.com>. 


\section{References}

Airey, J. (2011). Talking about teaching in English: Swedish university lecturers' experiences of changing teaching language. Iberica, 22, 35-54.

Bradford, A. (2016). Toward a typology of implementation challenges facing English-medium instruction in higher education: Evidence from Japan. Journal of Studies in International Education, 20(4), 339-356. https://doi.org/10.1177/1028315316647165.

Brown, H. (2017). Current trends in English-medium instruction at universities in Japan. OnCUE Journal, 10(1), 3-20.

Dearden, J. (2015). English as a medium of instruction-A growing global phenomenon. British Council.

Dearden, J. \& Macaro, E. (2016). Higher education teachers' attitudes towards English medium instruction: A three country comparison. Studies in Second Language Learning and Teaching, 6(3), 455-486. https://doi.org/10.14746/ssllt.2016.6.3.5.

Eaves, M. (2009). Learning styles technology and supporting overseas learners. Multicultural Education \& Technology Journal, 3, 61-73. https://doi.org/10.1108/17504970910951156.

Hanami, M. (2012). Brainstorming: Whether to teach in English or not. Mie Daigaku Kokusaikouryu- senta-Kiyou, 7, 93-107.

Hoare, P. (2003). Effective teaching of science through English in Hong Kong secondary schools. The Hong Kong University Scholars Club. Retrieved from http://hdl.handle.net/10722/39139 doi:10.5353/TH_B2976829.

Hsieh, H. F., \& Shannon, S. E. (2005). Three approaches to qualitative content analysis. Qualitative Health Research, 15(9), 1277-1288. https://doi.org/10.1177/1049732305276687.

lyobe, B., \& Li, J. (2018). Factors for success and sustainability of an elective English-medium instruction program. In A. Bradford \& H. Brown (Eds.), English-medium instruction in Japanese higher education: Policy, challenges and outcomes (pp. 161-179). Multilingual Matters.

Kling, J., \& Stæhr, L.S. (2012). The Development of the Test of Oral English Proficiency for Academic Staff. University of Copenhagen. Retrieved from https://www.academia.edu/2065305/The Development_of_the_Test_of_Oral_English_Proficiency_for_Academic_Staff.

Kuwamura, A. (2018). The future of English-medium instruction in Japan. In A. Bradford \& H Brown (Eds.), English-medium instruction in Japanese higher education: Policy, challenges and outcomes (pp. 161-179). Multilingual Matters.

Kuwamura, A. (2019). English-medium instruction and the expanding role of language educators. In P. Clements, A. Krause, \& P. Bennett (Eds.), Diversity and inclusion. (pp. 16-23) JALT.

Lu, Y. (2020). A case study of EMI teachers' professional development: The impact of interdisciplinary teacher collaboration. RELC Journal. https://doi.org/10.1177/0033688220950888.

Macaro, E. (2018). English medium instruction. Oxford: Oxford University Press.
Macaro, E., Curle, S., Pun, J., An, J., \& Dearden, J. (2018). A systematic review of English medium instruction in higher education. Language Teaching, 51(1), 36-76. https://doi.org/10.1017/ S0261444817000350.

Ministry of Education, Culture, Sports, Science and Technology. (2020). The status of educational reform in universities in 2017: An overview. Retrieved Feb 16, 2020, from https://www.mext.go.jp/ content/20200428-mxt_daigakuc03-000006853_1.pdf

Ministry of Education, Culture, Sports, Science and Technology. (n.d.). Global 30Project: Establishing University Network for Internationalization. Retrieved From https://www.mext.go.jp/ en/policy/education/highered/title02/detail02/sdetail02/1373894.htm.

Nakamura, I. (2003). Okayama University short-term special studying abroad program EPOK: Efforts for improvement and further issues of classes delivered in English. Okayama Daigaku Ryu-gaku Center Kiyou, 10, 61-77.

Sugimoto, S. (2020). Comparing student experiences of English-medium instruction in two Japanese universities. Language Education \& Technology, 57. 31-60. https://doi.org/10.24539/ let.57.0_31.

Tan, M. \& Lan, O. S. (2011). Teaching mathematics and science in English Malaysian classrooms: The impact of teacher beliefs on classroom practices and student learning. Journal of English for Academic Purposes, 10, 5-18.

Tange, H. (2010). Caught in the Tower of Babel: University lecturers' experience with internationalization. Language and Intercultural Communication, 10, 137-149. https://doi. org/10.1080/14708470903342138.

Tsuneyoshi, R. (2005). Internationalization strategies in Japan: The dilemmas and possibilities of study abroad programs using English. Journal of Research in International Education, 4(1), 65-86. https://doi.org/10.1177/1475240905050291.

Vinke, A. A., (1995). English as the medium of instruction in Dutch engineering education [unpublished doctoral dissertation]. Delft University of Technology, the Netherlands.

Yamamoto, Y. (2011). Challenges and direction of teaching academic subjects in English: A comparison of instructors who use mother language and those who don't. Meidai Shogaku Ronso, 93(1), 73-90.

Yip, D. Y., Coyle, D., \& Tsang, W. K. (2007). Medium of instruction on Science students: Instructional activities in science lessons. Education Journal, 35(2), 77-107.

Yonezawa, A. (2010). Much ado about ranking: Why can't Japanese universities internationalize? Japan Forum, 22(1-2), 121-137. https://doi.org/10.1080/09555803.2010.488948.

Yuan, R. (2019). Promoting EMI teacher development in EFL higher education context: Teacher educator's reflections. RELC Journal, 51(2), 309-317. https://doi.org/10.1177/0033688219878886 